\title{
O refluxo de uma tradição: o marxismo, o ensino de História e a ditadura empresarial-militar (1964-1975)
}

\author{
The decline of a tradition: marxism, history's teaching and the brazilian dictatorship (1964-1975) \\ Diego Martins Dória Paulo.
}

\begin{abstract}
Resumo
Este artigo tem como objetivo analisar o recuo da influência marxista sobre a pesquisa e o ensino de História durante a ditadura empresarial-militar brasileira (1964-1988). Para tanto, analisa as medidas que, por meio da coerção, buscaram interditar o marxismo como horizonte de pensamento no campo acadêmico ainda no rescaldo do golpe de primeiro de abril. Considera-se ainda as deliberações para o ensino e pesquisa de História no Brasil contidas na contrarreforma universitária de 1968 e no II Plano Nacional de Desenvolvimento, de 1975, como importantes para compreender o refluxo daquela tradição. Palavras-Chave: Ditadura empresarial-militar. Marxismo. Ensino de História.
\end{abstract}

O refluxo de uma tradição: o marxismo,

o ensino de História e a ditadura empresarial-militar(1964-1975). Revista Mosaico. 2015 Jul./Dez.; 06 (2): 11-17.

\begin{abstract}
\end{abstract}
This paper analyses the retreat of marxist's influence over the research and the History teaching in Brazil during the brazilian dictatorship (1964-1988). For then, analyses the governmental measures wich tries to intedict marxism as a cientific horizon on the academic field. So, the paper debates the deliberation for the history's teaching and researching in Brazil in the universitary reform act of 1968 and II PND, of 1975. Keywords: Brazilian dictatorship. Marxism. History teaching.

teóricos como Karl Marx, Antônio Gramsci e o agora "marxista" Paulo Freire, o Escola Sem Partido defende um ensino sem doutrinação, apartidário e livre de ideologias.

\section{$O$ refluxo de uma tradição: o marxismo, o ensino de História e a ditadura empresarial-militar (1964-1975)}

Ao se debruçar sobre um tema de estudo, o historiador invariavelmente aciona o dispositivo que o transporta para o passado. Esse trânsito, no entanto, é incompleto: não há como voltar no tempo sem carregar consigo suas inquietações do presente, seus pontos de vista, já moldados pelo que ocorreu. O presentismo é, assim, incontornável da análise historiográfica (e histórica). Falar sobre ensino de História a partir de 2015 é dedicar atenção a um tema fustigado pela ameaça da violência simbólica representada pelos PLs no 867/2015 e 1.411/2015, vulgarmente conhecidos pela alcunha "Escola Sem Partido".

Os mencionados projetos de lei, de autoria de deputados do Partido da Social Democracia Brasileira (PSDB), objetivam "impedir a doutrinação ideológica nas escolas". Alegando ser inconstitucional a atividade docente que visa conformar os educandos de acordo com uma visão de mundo específica, o raivoso texto se sustenta em uma anacrônica - ou ingenuamente interessada visão de neutralidade axiológica. Criminalizando, pois, as perspectivas sociais (e sociológicas) sustentadas em
No lado de cá da fronteira teórico-política, muitos já se incumbiram de desmistificar o discurso ideológico da causa. No entanto, ponto menos debatido do projeto de lei é aquele que pressupõe um predomínio cultural do marxismo no ensino, justificativa da intervenção da legislação contra essa doutrinação. Convém refutar também esse ponto do ataque conservador. Ora, se não podemos afirmar que há uma marginalização do marxismo no ensino básico de História - o que nos parece evidente, mas difícil de sustentar pela falta de provas confiáveis - podemos pelo menos negar sua hegemonia. Um indício que aponta nessa direção são as atuais pesquisas que demonstram o recuo do marxismo em ambiente acadêmico. ${ }^{1}$ Se aceitarmos uma relação mais ou menos direta entre os ensinos superior e básico, chegaremos à conclusão de que a tal doutrinação dos seguidores de Karl Marx pela história escolar seria dificilmente sustentável com o estrangulamento dessa concepção nas academias.

Há, porém, na memória universitária dos

MATTOS, Marcelo Badaró. As bases teóricas do revisionismo. O culturalismo e a historiografia brasileira contemporânea. In: MELO, Demian Bezerra de. A miséria da historiografia. Uma crítica ao revisionismo contemporâneo. Rio de Janeiro: Consequência, 2014. 
anos 1950 e 1960 indícios de que nem sempre foi assim. Roberto Schwarz, em artigo de 1978, defendia a existência de hegemonia cultural das esquerdas - especialmente do marxismo - naquelas décadas. Cito-o.

Apesar da ditadura de direita há relativa hegemonia cultural da esquerda do país. Pode ser vista nas livrarias de São Paulo e Rio, cheias de marxismo, na estreias teatrais, incrivelmente festivas e febris, às vezes ameaçadas de invasão policial, no movimento estudantil ou nas proclamações do clero avançado. Em suma, nos santuários da cultura burguesa a esquerda dá o tom. ${ }^{2}$

A aposta do autor merece reparos, haja vista que hegemonia do marxismo é uma proposição que descura totalmente o conceito gramsciano de hegemonia, dada a ausência de classes sociais - quem efetivamente pratica a hegemonia - em sua formulação, além dos limites óbvios de se identificar hegemonia - que diz respeito à capilarização de uma concepção de mundo - em um universo tão socialmente restrito quanto o "santuário da cultura burguesa". É menos problemático, no entanto, crer que a penetração do marxismo como quadro teórico era maior então do que atualmente o é - principalmente se levarmos em conta a atual grande influência do culturalismo, tanto na academia como no ambiente escolar. $^{3}$

Questionar-se o porquê desse refluxo foi tarefa autoimposta por outros que me antecederam. Marcelo Badaró Mattos, a título de exemplo, fornece uma resposta robusta e, ao meu ver, bastante fecunda, que relaciona a ascensão do neoliberalismo à maior influência do pós-modernismo nos ambientes escolares. Não é minha intenção negar essa asserção, ao contrário, trata-se de incluir um elemento que pode justificar o menor apelo do marxismo na atualidade, qual seja, o estudo da formação do que Pierre Bourdieu nomeou de habitus na universidade pública pela ditadura empresarial-militar brasileira. Assim, levantamos como hipótese que a estrutura das relações sociais inscritas na universidade pelo regime de 1964 favoreceu o abandono espontâneo do horizonte de pensamento marxista por parte considerável dos acadêmicos - ou ao menos deteve seu avanço.

Assim sendo, nega-se que o marxismo tenha perdido uma batalha das ideias, concebida em seu sentido estrito, ou seja, como disputa entre dois corpos teóricos no plano ideal, sem influência políticas mais concretas. Ao contrário, buscar-se-á na formação de disposições que favorecem uma forma de ver o mundo em detrimento de outras uma resposta possível para nossa charada.

2 SCHWARZ, R. Cultura e política, 1964-1969 in: SCHWARZ, R. O pai de família e outros ensaios Rio de Janeiro: Paz e Terra, 1978. p. 62

3 O histriônico Rodrigo Constantino, em sua falecida coluna em Veja, atacou o marxismo dominante no Enem. Para sustentar suas acusações, listou questões presentes na prova de 2014 que, para ele, no Enem. Para sustentar suas acusações, listou questões presentes na prova de 2014 que, para ele, de identidade, de minorias, enfim, corpo teórico típico da matriz culturalista, o que os melhor de identidade, de minorias, enfim, corpo teórico típico da matriz cultur
informados sabem que tem muito pouco em comum com o marxismo.

\section{A ditadura empresarial militar e a operação limpeza}

Para levantar os pontos que aqui desejamos, é preciso retornar ao momento de institucionalização do novo Estado, após o golpe empresarial-militar de 1964. Estamos nos primeiros anos da ditadura, quando os golpistas começam a ocupar os postos da sociedade política, reorientando as políticas públicas brasileiras de acordo com os interesses do novo bloco do poder, lastreado no capital multinacional e associado. Há extensa bibliografia que trata sobre o tema, sendo a obra de René Dreifuss, 1964: a conquista do Estado, a primeira a estabelecer relação direta entre o golpe e aquilo que, com Nicos Poulantzas, poderíamos chamar de nova ossatura do Estado brasileiro. ${ }^{4}$ Não há, assim, necessidade de recapitular todo o processo de formação do novo regime, bastando para os limites de nossa exposição lembrar que houve um redesenho do Estado de acordo com as classes que ora o animavam.

O impacto sobre as políticas públicas é lógico e necessário, sendo a implementação do Plano de Ação Econômica do Governo (PAEG), formalizado por ipesianos como Roberto Campos e Octávio Bulhões, novos ministros do planejamento e da fazenda, e que favoreceu o capital internacional e reduziu os ganhos reais dos trabalhadores, só um exemplo de tantos outros.

Nessa quadra histórica se aplicou a chamada "Operação Limpeza" (“Operation Clean-Up”, como foi batizada pelos estadunidenses que, aliados aos golpistas, participaram da ação). A operação significou a tentativa de extirpar do país qualquer político que tivesse ligação estreita com o regime anterior e o presidente deposto. Mais do que isso. Também interessava garantir a eliminação de qualquer propagador de ideologias formalmente proscritas pelos militares, notadamente as de esquerda, como o marxismo. Assim sendo, praticou-se no Brasil espécie de pente fino em diversas instituições, a fim de eliminar delas elementos com inclinações "subversivas".

É sabido que trabalhistas de esquerda, principalmente os que se empenharam na luta pelas reformas de base; comunistas; socialistas; intelectuais de esquerda; sindicalistas e representantes de movimentos sociais dificilmente escaparam de uma inspeção minuciosa por meio de Inquéritos Policiais Militares (IPM's). Todavia, precisar o número de detidos na operação é mais difícil, e os dados permanecem em debate - podendo variar de 5 mil a 50 mil presos, conforme o analista. Evitando fazer da tragédia um cálculo numérico, em que se pode estabelecer a repressão como mais dura ou mais branda, deve-se recordar que o

4 POULANTZAS, Nicos. Estado, poder, socialismo. Rio de Janeiro: Graal, 2000 
impacto representacional da repressão aqui é o que nos importa mais. Em outras palavras, não nos interessa, para os limites do trabalho, quantificar exatamente sobre quantas pessoas o braço da ditadura pesou mais forte, mas ressaltar a espetacularização da repressão como meio de impor uma sociabilidade baseada em novas condutas. Nesse sentido, as praias cariocas e santistas foram importantes ferramentas da construção da nova ordem, já que em seus mares navios podiam ser vistos ancorados próximos à costa. Com cadeias abarrotadas, a solução encontrada pelos dirigentes militares foi trancafiar os inimigos políticos em embarcações que faziam às vezes de prisões ${ }^{5}-\mathrm{e}$ forneciam, ao alcance dos olhos, uma constante lembrança do que não se deveria ser.

Outro sinal do clima geral de medo instaurado pelas perseguições foi a busca por tentativas de se livrar de "provas" de subversão as mais variadas, que incluíam jornais, revistas e, principalmente, livros. A conduta mais adequada pela cautela então reinante era queimar documentos com qualquer inclinação "subversiva", sobretudo os de orientação marxista. De acordo com um dos especialistas no tema, "houve casos de livros enterrados, enviados a parentes insuspeitos, e mesmo de pessoas que, em total desespero, queimaram não só os documentos, como também os livros". ${ }^{6}$

A preocupação em se livrar desse material não era excessiva: nas batidas da polícia de então eram frequentes revistas a bibliotecas, que eram investigadas à procura de livros considerados deletérios pelos agentes repressivos. Mesmo instituições públicas foram alvos de profundas - e geralmente danosas para o acervo "investigações". A biblioteca da cátedra de história moderna e contemporânea da Faculdade Nacional de Filosofia (FNfi), da Universidade do Brasil (UB), atual UFRJ, sob responsabilidade de Maria Yedda Linhares, foi depredada por ação dos órgãos da repressão. ${ }^{7}$

O clima geral de instabilidade encetado pelo novo regime foi logo tema a ser abordado pelos cronistas da época. Um dos intelectuais a retratarem a insegurança generalizada foi escritor católico Alceu Amoroso Lima. Em artigo no Correio da Manhã de maio de 1964, o autor cunhou a expressão "terrorismo cultural" para expressar os abusos, a brutalidade e a violência de um modo geral que eram utilizadas sob a justificativa de combate ao comunismo. A expressão foi popularizada por Nelson Werneck Sodré, que, em artigo da Revista Civilização Brasileira de 1965, utilizou a expressão de Amoroso Lima para retratar as perseguições e os hábitos de censura e a autocensura que dela foram decorrentes. ${ }^{8}$

Dentre as diversas instituições vasculhadas na procura por "inimigos internos", a que mais interessa aqui é a que atinge as universidades. A atenção dos

\footnotetext{
5 MOTTA, Rodrigo Patto Sá. As Universidades e o regime militar. São Paulo: Zahar, 2014. P. 24 6 Idem. Ibidem. p. 27

7 Francisco Falcon concedeu entrevista a Rodrigo Patto Sá Motta, na qual revelou o acontecido. Mais em MOTTA, Rodrigo Patto Sá. Op cit. P. 364 8 Idem. Ibidem. p. 28
}

vencedores de primeiro de abril foi atraída para as instituições de ensino superior por diversos fatores, dentre os quais o crescimento de importância numérica dos campi universitários. Ora, desde o fim da Segunda Guerra Mundial o número de matriculados cresceu notavelmente, fazendo com que sua proporção no todo social se tornasse significante. A localização preferencial em centros urbanos também aumentava sua importância, especialmente aos olhos de um governo balizado por pensamento tático do tipo militar. ${ }^{9}$

A intervenção na vida acadêmica principalmente moldada pela caça aos "subversivos" - se tornou assim corriqueira. Invasões a UnB foram inúmeras. Identificada como meca do nacionaldesenvolvimentismo de esquerda, a universidade, fundada por Darcy Ribeiro e outros intelectuais alinhados com o governo de João Goulart, era importante polo de defesa das reformas de base. Isso lhe custou a tranquilidade e a manutenção de sua autonomia já nos primeiros anos do novo regime. Ainda em 1964, a polícia militar do Distrito Federal e o exército, com armas em punho, invadiram as dependências da universidade. Uma vez tomados os prédios, foi feita uma varredura entre alunos e professores, com espécie de seleção daqueles que iriam para as prisões e outros que conservariam sua liberdade.

Um ano depois o fato se repetiria, mesmo após as cassações decretadas quando o AI-1 foi baixado, retirando nove professores dos quadros da universidade, além do reitor Anísio Teixeira e o vicereitor Almir de Castro. ${ }^{10}$ De acordo com Darcy Ribeiro, um dos idealizadores da universidade, o projeto educacional incomodava o regime, principalmente por se fundamentar no pensamento de Paulo Freire, à época identificado politicamente com correntes da esquerda nacional. ${ }^{11}$

Na Faculdade Nacional de Filosofia (FNfi), da Universidade do Brasil, atual UFRJ, a coerção estatal também orientou os estudos. Um dos episódios mais comentados da época foi a invasão do campus do Largo de São Francisco e a prisão de diversos alunos e professores vistos como inimigos da pátria. Identificada pelos golpistas como baluarte dos comunistas no meio universitário, a FNfi teve ainda parte de sua biblioteca depredada e suas atividades de pesquisa postas sobre constante supervisão de representantes dos militares. Quando as aulas foram autorizadas, era comum estudantes observarem soldados na porta da universidade e mesmo no interior de salas de aula, como denunciado por diversos jornais, dentre eles A Última Hora. ${ }^{12}$

A operação limpeza se direcionava para uma varredura de alto a baixo na estrutura acadêmica brasileira. Assim sendo, era natural, dentro da lógica

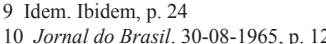

11 RIBEIRO, Darcy. O Brasil como problema.Brasília: Editora UnB, 2002, p. 36 12 MOTTA, Rodrigo Patto Sá. Op Cit. P. 31
} 
do regime, que o MEC sofresse o mesmo tipo de intervenção. Como corolário do processo, ministros nomeados por militares - primeiro, o ex-reitor da USP, Luís Antônio da Gama e Silva, e depois o reitor da Universidade Federal do Paraná, Flávio Suplicy de Lacerda - em seus discursos de posse, sinalizaram para a necessidade de "sanear o comunismo" das instituições responsáveis pela formação da juventude. ${ }^{13}$ Não causa estranhamento que ambos tivessem ligações tanto com a Escola Superior de Guerra (ESG) quanto com o IPES, organizações que articularam a conquista e a reorganização do Estado.

Também o controle da Diretoria de Ensino Superior do MEC (DES/MEC) é indicativo do tipo de academia que se preconizava. Com o golpe de 1964, nomes ligados ao que era entendido como desenvolvimento autônomo brasileiro e a defesa das reformas de base, ocupantes da diretoria durante o governo João Goulart, foram substituídos por nomes como Muniz de Aragão. Palestrante crônico da ESG, a escolha do professor e pesquisador para o cargo evidencia a estreita relação entre o novo projeto de educação para o ensino superior brasileiro e as teses da ESG, que, além de estreitamente relacionadas ao projeto classista do IPES, postulavam a existência de um inimigo interno - "marxistas" e "comunistas" - que deveria ser combatido com táticas de contrarrevolução. A trajetória de Muniz de Aragão, aliás, demonstra a influência esguiana na estrutura acadêmica brasileira durante o regime militar: de diretor da pasta de ensino superior do MEC, Aragão logo ascenderia para ministro da educação, posteriormente sendo lotado como reitor da Universidade Federal do Rio de Janeiro, de onde deu prosseguimento às perseguições políticas e ao saneamento do marxismo, olhando de perto especialmente o campus da Faculdade Nacional de Filosofia.

É lógico pensar que o clima do "terrorismo cultural", encetado pela "operação limpeza" trouxe modificações importantes para a vida acadêmica brasileira. Os impactos do novo regime são medidos não só pelo número de prisões e jubilação de alunos, mas também pela mudança de hábito que se seguiu ao clima de perseguição política. Delações entre professores e alunos se tornaram corriqueiras. Mais especificamente falando, docentes, por ideologia ou senso prático, encaparam o projeto militar, combatendo interna e preventivamente, de modo ostensivo ou mais ameno, colegas suspeitos de praticar "comunismo". É o caso dos reitores da USP e da UFPR, já mencionados, que praticaram verdadeiras operações de limpeza autônomas. ${ }^{14}$ Mesmo intelectuais consagrados se aliaram ao regime, como Gilberto Freire, que se tornou ferrenho crítico dos "agentes do comunismo internacional

no Brasil". Entre os alunos, o clima de delação não era diferente. Em alguns casos, colegas não apenas assinaram cartas de denúncia, como compareceram a julgamentos para testemunhar contra réus, acusados de "subversivos".

Nessa ambiência, a inflexão teórica identificada na vida acadêmica brasileira, especialmente nos cursos de História, como logo se mostrará, torna-se compreensível. Ora, argumenta-se aqui que a interferência ostensiva a ditadura favoreceu certas disposições no interior do campo acadêmico, notadamente o abandono de determinadas opções teóricas - o marxismo sendo a mais flagrantemente relacionada à violência do Estado. Nesse sentido, a conjunção de perseguição política, destruição de livros e bibliotecas, invasões de campi universitários, prisão de professores e alunos arrematava todo um clima que desabonava qualquer tipo de pensamento crítico, relacionando-o diretamente com o perigo da repressão.

\section{A contrarreforma universitária de 1968}

Aceitar a tese de que a ditadura empresarialmilitar significou uma inflexão profunda na história do Brasil, legando aos dias de hoje estruturas sociais, econômicas e políticas pelas quais se movimentam os brasileiros, joga luz diferente sobre o processo histórico de redemocratização e constituição atual do país. São profundos os ecos do passado que atormentam - ou agraciam - a vida dos que couberam viver por aqui. E o impacto que ora mais interessa é sobre a esfera acadêmica, mais especificamente o campo da História, tão afetado pelos desmandos do regime que se iniciara com a queda de Jango. A hipótese geral que norteia esse trabalho é a de que a ditadura empresarial-militar impactou decisivamente no campo da História, a ponto de influenciar nas opções teóricas ainda hoje feitas, mais ou menos de modo consciente, pelos pesquisadores da área.

A consequência que mais interessa aqui explicar é a retração do marxismo no campo da historiografia brasileira. Não tanto como resultado de derrotas no confronto de ideias, mas como produto de um processo duplamente determinado. Em primeiro lugar por seu impacto mais imediato, pela repressão levada a cabo pelos agentes públicos prenhes da ideologia ipesiana e esguiana, que tinham como interesse "eliminar o marxismo da universidade brasileira". ${ }^{15}$

Num segundo momento, discute-se aqui o impacto do habitus acadêmico específico criado pelos procedimentos persecutórios implantados pela ditadura, mas também por sua face de fomento. Assim, o marxismo foi prejudicado pelos procedimentos de censura e autocensura que os pesquisadores sofreram

15 LEHER. Roberto. Ditadura militar de 1964: uma universidade para o capitalismo dependente. In: IASI, Mauro Luís; COUTINHO, Eduardo Granja. Ecos do Golpe. A persistência da ditadura militar IASI, Mauro Luís; COUTINHO, Eduardo Granja. Eco
50 anos depois. Rio de Janeiro: Mórula, 2014. p. 136 
e/ou se impuseram, seja para escaparem da perseguição política, seja para terem acesso a bolsas de estudo de órgãos de fomento então criados para selecionar e custear pesquisadores por critérios subjetivos, inclusive opções teóricas. Como já mencionado antes, com a diretoria da divisão de ensino superior do MEC nas mãos de um representante da burguesia ipesiana, inoculado com noções militares típicas da Doutrina de Segurança Nacional e Desenvolvimento, é compreensível que se depreenda a redução dos financiamentos a pesquisas de aporte crítico ao capital.

Em outras palavras, defende-se que, após o golpe de 64, o regime que dele surgira estabeleceu estreitos laços com a universidade. São exemplos do interesse governamental nesse espaço social a contrarreforma universitária de 68 e a criação de agências de fomentos já listadas. A preocupação de estabelecer critérios ditos técnicos como vieses de análises subjetivas também revela uma preocupação política: o véu do tecnicismo, na verdade, recalca opções ideológicas com o argumento do cientificismo neutro.

A contrarreforma universitária de 1968 representou um período de acirramento das perseguições políticas - principalmente por sua combinação com o AI-5 - e de estruturação do aparato de financiamento de pesquisas, que posteriormente seria hegemônico na academia brasileira. Assim, Roberto Leher sintetiza as transformações trazidas pela medida.

A chamada reforma universitária foi constituída não só pela lei 5.540/1968 e os decreto que regulamentam. Muito mais abrangente, abarcou desde os elementos abertamente coercitivos, como o AI-5 e o decreto 477, até mudanças operadas no âmbito do Conselho Federal de Educação ${ }^{16}$

Por conseguinte, essa contrarreforma universitária representa uma etapa decisiva na inflexão acadêmica trazida pela ditadura. Aliado aos períodos fracamente persecutórios, como a já mencionada "Operação Limpeza" e o decreto do AI-1, as medidas do decreto 5.540/68 regulamentaram a heteronomia do campo universitário, dado que o financiamento de pesquisa passava a ser função de agências de fomento. Constituise, assim, o duplo ataque do regime à universidade brasileira - de um lado, a coerção; do outro, a busca pelo consentimento em relação a uma nova ordem e um novo padrão de pesquisa acadêmica, via financiamento de teses alinhadas com os interesses dos golpistas - o que tem como corolário o prejuízo ao pensamento desviante.

Todavia, a política de fomento depende de uma etapa necessária, que lhe é anterior. Trata-se da retirada de autonomia da universidade, desde então dependente dos recursos públicos que não mais administra, mas recebe de agências ligadas à pasta de
Ciência e Tecnologia, administrada por personagens comprometidas com o projeto do regime empresarialmilitar, como João Paulo dos Reis Velloso, ministro do planejamento da ditadura entre 1974-79 e educado nos moldes ipesianos. Identifica-se, assim, no período referido, a consubstanciação de duas esferas sociais até então distintas, a saber, a do planejamento econômico e a do planejamento científico. Sintomático da visão mercadológica que seria imposta à educação pelo referido ministro, que ao mesmo tempo administrava agencias de fomento que com a retirada de recursos e da autonomia universitária se tornaram fundamentais para o desenvolvimento da ciência no Brasil.

A obra da ditadura no campo acadêmico e educacional se aprofundaria com o segundo Plano Nacional de Desenvolvimento, em vigência entre 1975 e 1979. Este representou a mencionada inflexão também por conta da ofensiva ideológica nele articulada. Em suas diretrizes de segurança interna, constava o combate a ideias perniciosas ao desenvolvimento econômico do Brasil. O que não poderia correr risco, é claro, era a chamada a modernização conservadora pela qual passava o país, isto é, a adequação de suas estruturas econômica, política e social à agenda do capitalismo monopolista internacional. Nesse sentido, a mobilização popular era vista como óbice à margem ideal de progressocapitalista. Portanto, deveria ser combatida tanto no plano concreto das lutas políticas - daí a repressão ser recurso corriqueiro às greves que marcaram a década de 70 no Brasil - quanto na esfera das ideias. Nesse âmbito, especificamente, as teorias "populistas" e, principalmente, marxistas eram identificadas como alvos a serem eliminados, devido à sua incompatibilidade com o planejamento social encetado pelo regime. As palavras de Roberto Leher ilustram como se deu as medidas de controle com o segundo Plano Nacional de Desenvolvimento.

Com o II PND e o controle dos órgãos de fomento por professores com vínculos com os tecnocratas da ditadura, as áreas apoiadas pelas políticas de fomento à C\&T [ciência e tecnologia] se enraizaram nas universidades, sobretudo pela pós-graduação, ensejando o I Plano Nacional de Pós-Graduação (PNPG, 1975), que, conforme orientação governamental, deveria ser implementado de modo a assegurar "severa vigilância", objetivando formar os docentes que atuariam na pós-graduação e, principalmente, submeter os programas, já em número expressivo, a regras gerais unificadas a partir da Capes e do Desenvolvimento de Assuntos Universitários do $\mathrm{MEC}^{17}$

As determinações imputadas pelo segmento educacional do II PND difundiu o que Leher chamoude "certo ethos acadêmico em que o que é dado a pensar deve estar emoldurado pelos programas de fomento e de reconhecimento da legitimidade do aparato 
administrativo erigido", ${ }^{18}$ justo por contar com quadros internos à universidade que apoiaram o projeto de modernização conservadora. Ainda de acordo com o mesmo autor muitos docentes que viveram a ditadura, inclusive muitos que lutaram contra ela nos anos 1960 e 1970, induziram, de distintos modos, os seus colegas mais jovens a não se perguntarem sobre as coisas que poderiam levantar problemas, assuntos e coerções que "deveríamos esquecer". ${ }^{19}$

Esterilizada em seus viés crítico, a universidade passou a se dedicar em criar vínculos com o setor produtivo, principalmente porque esse estreitamento de relações era bonificado pelos órgãos de fomento, que investiam mais pesadamente nos estudos de perspectiva utilitarista, isto é, que auxiliam no desenvolvimento de tecnologias que maximizavam a acumulação de capital. ${ }^{20}$

Alguns autores perceberam a inflexão que se operava no campo teórico. Em Universidade Brasileira: reforma ou revolução? (1975) Florestan Fernandes aponta os impactos da reforma universitária implementada pela ditadura. De acordo com o sociólogo, com a perda de autonomia financeira e a cassação de muitos docentes, a academia nacional tinha sido extirpada de seu viés crítico, produzindo desde então, de modo geral, discursos de defesa da ordem, não de seu questionamento. Carlos Benedito Martins, pensando sobre os aparelhos repressivos e sua atuação na seleção de pessoas aptas a academia, com óbvio viés político, destacou que a repressão a alunos e professores foi constituinte do período militar, sendo ampliada pelas reformas que a ditadura realizou no meio acadêmico, principalmente a partir de 1968.

Com relação ao dispositivo repressivo, vale mencionar o Decreto n. 4.464/64, que extinguiu a União Nacional dos Estudantes (UNE); o Decreto n. 228/67, que limitou a existência de organizações estudantis ao âmbito estrito de cada universidade; o Decreto n. 477/69, que impôs severas punições aos estudantes, professores ou funcionários que desenvolvessem atividades consideradas hostis ao regime militar, com a criação, no interior do $\mathrm{MEC}$, de uma divisão de segurança e informação para fiscalizar as atividades políticas de professores e estudantes nas instituições. Houve, igualmente, aposentadorias compulsórias de professores consideradosnocivosaoregimemilitaremváriasuniversidades públicas (Fávero, 1995; Sanfelice, 1986; Fernandes, 1984). ${ }^{21}$

Castrada de tal forma, a academia brasileira

18 Idem. p. 143

19 Idem. Ibidem.

$20 \mathrm{O}$ padrão de financiamento, mesmo no setor produtivo, também mudou com o regime militar. Se antes, as universidades tinham autonomia para gerir recursos próprios, com o advento da ditadura as agências de fomento e iniciativa privada ocuparam importante fatia do patrocínio, como most tabela divulgada pelo Correio da Manhã, em 24 de novembro de 1968. De acordo com o jornal, A principal fonte de auxílio da Coordenação dos Programas de Pós-graduação de Engenharia da UFR. tem sido o Banco Nacional do Desenvolvimento Econômico, único banco do mundo que investe na educação. O BNDE paga salários, compra equipamentos e mantém a biblioteca da COPPE sempre atualizada" (p. 20) A seguir a publicacão, no biênio de 65/67, a participação das principais fontes de recurso da COPPE foi a seguinte: BNDE 43\%, Assistência técnica estrangeira 24\%, UFRJ 16\%, CAPES CNPn (boles de estdo) 14\%, ind

21 Ver mais em MARTINS, Carlos Benedito. A reforma universitária e a abertura ao ensino privado no Brasil. Educ.Soc. vol.30no.106Campinas, Jan /Apr.2009. deixou de se perguntar sobre os padrões de acumulação; não mais interpelou o tipo de desenvolvimento industrial implementado no Brasil, com todas as contradições; deixou de atuar em um sentido anti-hegemônico em relação ao capitalismo monopolista, por não mais desnaturalizar suas relações com a sociedade. Isso, sem dúvida, contribuiu muito para a apuração de um habitus específico.

\section{Considerações finais}

Em artigo sobre o espaço social e o poder simbólico, Pierre Bourdieu avança a noção de habitus, definindo-a como um conjunto de disposições e estruturas mentais que são adequadas a um determinado lugar social, tendo relação direta com sua estrutura política e econômica (BOURDIEU, 2004). Em outras palavras, o habitus é a contrapartida comportamental da estrutura social que organiza a ação coletiva de sujeitos inscritos em determinado campo. Assim sendo, todo desenvolvimento econômico, político e social conforma o hábitus, uma forma de conduta que direciona a ação social dos sujeitos.

Por se autoconsiderar um pensador estruturalista construtivista (BOURDIEU, 2004), Bourdieu não esquece a contrapartida do habitus - e da ação dos sujeitos - em relação à estrutura que os conforma, lembrando que as ações orientadas por aquelas disposições atuam, dialeticamente, modificando as estruturas que as lastreiam. Suas observações, portanto, permitem análises, ao mesmo tempo, extremamente dinâmicas e profundamente comprometidas com uma perspectiva histórica.

Ao analisarmos a ditadura empresarial-militar com base nessas observações, vemos que os aparelhos de Estado foram preenchidos por membros do bloco golpista, composto por ipesianos, esguianos, setores burgueses e militares aderentes a um projeto societário específico. Em posse desses cargos públicos, as políticas que daí derivaram tinham nexo lógico com aquele planejamento, organizado em associações da sociedade civil, que, agora, legando seus quadros à sociedade política, universalizavam seus pontos de vista particulares - estratégia social bem explicada por Antônio Gramsci (2002), que, justamente por isso, amplia a noção tradicional de Estado para englobar as organizações da sociedade civil, os aparelhos privados de hegemonia, responsáveis por organizar as vontades coletivas e formar quadros para políticas públicas de interesse classista bem definido.

Ao instrumentalizar, nesse quadro teórico, a noção de habitus, vemos que não só os quadros políticos que ocuparam o Estado - principalmente o MEC, que aqui nos interessa mais de perto - implementaram um conjunto de soluções para os problemas do país baseado 
na agenda de classe que lhes formou enquanto quadros políticos como também suas políticas públicas fizeram emergir habitus especificos nos setores que atingiram. No caso da academia, a contrarreforma de 1968 e o II PND deliberaram francamente sua articulação ao mercado pautando suas condutas pelo viés do utilitarismo para o capital. Além disso, a própria lógica de produtividade e cientometria introduzida favoreceu certas disposições que já estavam incrustadas no aparelho acadêmico aquela altura - já amplamente expurgado de elementos comprometidos com o marxismo por medidas repressivas, como a mencionada Operação Limpeza. A produção científica tinha uma forma preferencial, que, embora não única e nem imposta, difundia-se por encontrar estudantes e professores mais dispostos a nela se adequarem - ainda que tal disposição tenha se forjado com métodos bárbaros, como se viu na metade inicial deste artigo.

Nesse sentido, por meio dessas linhas se tentou acrescentar um elemento de análise para o refluxo do marxismo como horizonte teórico no campo acadêmico. Relacionamo-nos com os interesses - e necessidades de classe que pautaram as políticas públicas da ditadura empresarial-militar. Por conseguinte, vemos que a influência do regime instaurado em 1964 sobre o campo educacional vai mais além do viés tecnicista imposto à forma de ensino: também certas correntes teóricas foram perseguidas e desabonadas desde a esfera acadêmica, o que se refletiu mais ou menos diretamente no ensino de História em níveis inferiores.

\section{Referências}

BOURDIEU, P. Coisas Ditas. São Paulo: Brasiliense, 2004.

GRAMSCI, A. Cadernos do cárcere. Rio de Janeiro: Civilização Brasileira, 2002, 6v.

LEHER. R. Ditadura militar de 1964: uma universidade para o capitalismo dependente. In: IASI, Mauro Luís; COUTINHO, Eduardo Granja. Ecos do Golpe. A persistência da ditadura militar 50 anos depois. Rio de Janeiro: Mórula, 2014.

MARTINS, C. B. A reforma universitária e a abertura ao ensino privado no Brasil. Educ.Soc.vol.30no.106CampinasJan./Apr. 2009.

MELO, D. A miséria da historiografia. Uma crítica ao revisionismo contemporâneo. Rio de Janeiro: Consequência, 2014.

MOTTA, R. P. S. As Universidades e o regime militar. São Paulo: Zahar, 2014

POULANTZAS, N. Estado, poder, socialismo. Rio de Janeiro: Graal, 2000. RIBEIRO, D. O Brasil como problema.Brasília: Editora UnB, 2002.

SCHWARZ, R. O pai de família e outros ensaios. Rio de Janeiro: Paz e Terra, 1978. 